Sumerianz Journal of Economics and Finance, 2021, Vol. 4, No. 4, pp. 149-156

$\operatorname{ISSN}(e): 2617-6947, \operatorname{ISSN}(p): 2617-7641$

Website: https://www.sumerianz.com

DOI: https://doi.org/10.47752/sjef.44.149.156

(C) Sumerianz Publication

\title{
The Use of New Technologies by Companies: What Threshold?
}

\author{
Martin Njocke \\ $\mathrm{PhD}$ in Economics Lecturer Researcher University Institute of Technology University of Douala, Cameroon \\ Email: martinnjocke2002@yahoo.fr
}

\section{Article History}

Received: October 17, 2021

Revised: December 14, 2021

Accepted: December 17, 2021

Published: December 23, 2021

\begin{abstract}
New information and communication technologies represent a major tool for companies which are involved in a competition by quantities. Their effect is diversely appreciated following the nature of the information (symmetrical or asymmetrical). This work allows us to highlight the Solow paradox which stipulates substantially that: « you can see the computer age everywhere except in the productivity statistics ». that can be understood as: "new information and communication technologies can be seen everywhere except in the productivity statistics ». The main result of this paper clearly shows that beyond a given threshold, the use of technology by companies are no longer profitable because market shares remain stable.
\end{abstract}

Keywords: New technologies index; Threshold; Productivity.

\section{Introduction}

Since the 1990s, we have witnessed the rise of a new cycle of innovation: that of the information and communication industries which are at the heart of the new economy.

Some examples developed in this work such as the microcomputer, electronic commerce, electronic messaging, Internet marketing and advertising, videoconferencing, the virtual assistant, the delivery robot and many other examples that we have not cited here assume that the production costs borne in the new economy are significantly lower than the production costs borne in the traditional economy (that is to say, one that does not integrate new technologies).

The central question in this work is to find the threshold of use of new technologies of companies in a competitive environment.

The objective being to show that this use of ICT beyond a certain threshold is no longer profitable for the company insofar as its market share and its profit evolve less than proportionally compared to a more marked use of new technologies.

The appearance of the knowledge society and the globalization generates important changes in our daily life.

ICTs refer to all the tools used for bodiless messages transmission and are subdivided into three categories: audio-visual (tone and image) presents, computer science (coding and information treatment) organizes and telecommunications (Internet and networks) bring together (Dieuzeide, 1994). They represent a set of all technologies which assure communication, storage transmission, creation, the sharing or the exchange of information (Beheton, 2010).

Many writings which define ICTs seem not to have a consensus. This is not a new debate and since late 1970s, the introduction of computer in school led to the use of peripherals such as printers, floppy disks, scanners, etc. Information technologies (IT) associate computer science technologies, to microelectronics, and telecommunications (Castells, 1998). Anderson (2010), on the other hand thinks that ICTs represent all the technologies allowing to communicate or exchange information with others.

The adoption of ICT utilitarian approach and the multitude of different definitions leads to the following suggested global definition: TICs combine all the technologies related to computer science (materials and software's) allowing the treatment and information storage, exchange, transmission and the sharing of information, communication and the dissemination of information.

For the majority part of companies sector in $\mathrm{OECD}^{1}$ area, ICTs are widely spread and are more and more utilized to ameliorate the productivity and the performance of companies. Technological progress in goods and services derived from ICT is fast, contributes to lower prices and arouses a whole range of new applications.

The electronic commerce progress between companies continues, the broadband distribution becomes fast. The introduction of more powerful microprocessors in the market will contribute to ameliorate productivity gains. Economic impacts of new technologies measured up to date, differs according to OECD members.

\footnotetext{
${ }^{1}$ OECD: Organization for Economic Cooperation and Development
} 
Investment in ICT and their intelligent use, increases the capital stock made available to workers, thus ameliorating work productivity.

Many studies show that the use of ICT helps efficient companies to obtain import market shares compared to less productive companies, ameliorate the global productivity, widens their product line in personalization of services it offers in order to better answer to market demand. This intensive use of new technologies is closely related to the adaptability of companies to the demand trends.

It seems like companies invest heavily in ICT either to compensate unlack of qualifications or to answer to respond to competitive pressures, either because they do not have a clear market strategy.

Our previous works allowed us to highlight the Solow paradox, that stipulates essentially: «You can see the computer age everywhere except in the productivity statistics», which can be understood as: "new information and communication technologies can be seen everywhere except in the productivity statistics ».

In the framework of a restricted model such as Cournot duopoly or the Bertrand duopoly, we came out with the following results:

a) In a situation of minimal information (when no competitor knows the reaction function of the other), the use of new technologies has a profitable impact for the company that uses them more intensively compared to its competitor, in the sense that its market share and its profit increase meanwhile the market share and profit of the competitor decrease.

b) Still in a situation of minimal information, when both companies get involved in a technological race, that is in an intensive use of new technologies, it seems that there is no impact on the competitiveness of companies in the sense that none of them are advantaged. Market shares remain almost identical.

c) In a situation of asymmetric ${ }^{2}$ information (one competitor knows the reaction function of the other), the use of new technologies is not profitable to the company whose reaction function is known, whatever its level of use of ICT (whether it uses them more or less that than the leader). We will see appear here, the Solow paradox whose main idea is that the use of new technologies dones not result to increase of productivity.

In this paper, we are interested in the level of use of new technologies. For a company, adopting the technology in a production process is one step, the other is to detect the use threshold.

The main question which comes out is the following:

Can a Company Indefinitely Use ICT? In Other Words, is there a Limit to the Use of ICT?

Our work is structured as follows:

Firstly, the impact of ICT on production factors, secondly the chosen model and finally the obtained results.

\section{The Impact of ICT on Production Factors}

In this paragraph, we present a range of examples of the impact ICT on variable costs and fixed costs.

\subsection{Impact of ICT on the Capital Factor (Njocke, 2010) \\ 2.1.1. The Portable Computer}

The portable computer today plays a multitude of functions and this, in an increasingly faster way compared to the old generations of machines.

A new machine is equivalent to two (or even more) old machines in term of usage of time; one spends less time than previously and we consider this as a fall of the quantity of capital (and thus a drop in variable cost).

\subsubsection{E-Commerce}

E-commerce, unlike traditional commerce leads to lower variable and fixed costs of production. The acquisition of a commercial counter on the internet will cost less than that of a traditional commercial counter: the existence of «walls», salesmen or women not being necessary in electronic commerce. The «walls » here refer to the buildings and expenses related to the maintenance of these buildings. These are fixed costs and they are significantly lower in the case of electronic trade.

\subsubsection{Electronic Messaging and the Exchanges of Files (ftp)}

Electronic messaging on the global scale, commonly called e-mail makes it possible for subscribers to communicate internally and externally at a low variable cost: a user in Douala pays the same price to send an e-mail to Yaoundé or Paris, whether the receivers are associates, employees, customers, etc. The electronic mail now presents itself as a complement to the fax in companies while being an economic mode of communication. The Internet also allows the transfer of files (ftp: file transport protocol) whose electronic volume is important. This allows for example a team geographically dispersed to meet and work by sending documents on any support (written, sound or video): This is the principle of virtual offices. Once more, in the case of ICTs, the fixed costs (virtual offices) are almost null compared to the traditional economy with high fixed costs (real offices).

\subsubsection{Video Conference}

Videoconferencing comprises of two techniques: the first being the video phony which allows seeing and dialoguing with the interlocutor and the videoconferencing which allows meetings with several people (terminals).

\footnotetext{
${ }^{2}$ Asymmetric information allows to define two types of agents: one agent having information concerning its competitor called « leader », and one agent not having any information on its competitor called «follower ».
} 
There are several applications of the videoconferencing such as educational television (remote training that allows the reduction of the costs of training students), the telemedicine which enables medical experts to exchange information and render health services remotely and thus reduce the cost of health services.

\subsubsection{Internet, Advertising and Marketing}

\subsubsection{The Internet and Adverstising}

Rather than paying pages of publicity spots or send prospection files to its potential customers, the company sends them computerized messages which are relatively less expensive. If we consider that the more advertising is done, the greater the sale of the produced quantities, then the publicity expenditure is a variable cost. We thus witness a fall in variable costs (from the point of view of the factor capital).

\subsubsection{The Internet and Marketing}

Today, the main factor that determines success is no longer the size of the company, but its reaction speed. The production cycles are continuously being shortened in order to meet the needs of the market. In fact, there are the companies that will be able to benefit from this new era that will be more performing on the market. The internet allows the company to have a commercial presence on the world market and its use (the internet) is the key of the development of the company, if not its survival. In fact, the internet offers companies the means of selling and promoting their products in a globally and develop their market without having to support significant commercial costs (these various costs are cited above). Moreover, the internet offers companies the means of acquiring information necessary for the management of their business in an unlimited manner. Technical, economic and commercial information is available free and many companies start to reduce their research expenditure, which are regarded here as fixed costs. In the light of these examples, we note that the quantity of capital required for the production of an additional unit of output has dropped, compared to the traditional economy i.e. the economy that does not integrate ICTs. Consequently, the new technologies mentioned above contribute to reduce production costs for all types of companies operating in any branch of industry (primary, secondary or tertiary).

\subsection{Impact of ICT on Work Factor (Njocke, 2020)}

\subsubsection{Virtual Assistant}

A virtual assistant or conversational robot is a computer program whose aim is the simulation of a smart conversation with human. This technique is already used by $80 \%$ of companies in developed countries in their Web marketing strategy. This conversation can be of an audio or text form. These applications more and more appear in Web sites or in instant messengers (Facebook, Messenger and others) and are notably used to handle customer relationship management.

The virtual assistant ensures un a 7 days on 7 service, 24 hours on 24 and it is appreciated for different reasons: dissemination of information nearby internets users, visitor's assistance in their order taking, response to questions for ongoing orders and mostly conditions concerning returned goods, information and / or partners assistance by intranet or extranet. $30 \%$ of virtual assistant users take place in the evening or at night, out of switchboard opening hours. To EDF (Electricité de France) Individuals, virtual assistance named Laura, answers up to an average of 10000 questions per day on billing, opening or contracts modification, etc.

\subsubsection{Delivery Robot}

In China, the delivery robot is currently replacing the traditional delivery man under some conditions. It an autonomous machine with wheels, equipped of GPS, cameras and radars. Consignees are more and more numerous to receive parcels, meals and other from robot whose height is similar to a small washing machine, at a speed of about $3 \mathrm{~km} / \mathrm{h}$. A client among many others, delighted with the prowess of this machine, however regrets that it could not deliver at the door of the apartment as the traditional deliver man was used to do.

The consumer selects products to be delivered via a mobile phone and pays online. The supermarket which receives the order places the goods into the robot which will deliver in 3 to 4 minutes time at the foot of the building located at about 200 meters. To collect his package, the consignee clicks on the link via his mobile phone to unlock the safe. It is noted that in China, $52 \%$ of inhabitants do their purchases online versus $14 \%$ in the rest of the world.

The highest speed of this robot is $12 \mathrm{~km} / \mathrm{h}$ and cannot work 24 hours on 24 . Thus, the human deliverer is not totally ousted from the job market and continues to partially play his role.

In the light of these two examples, and some others that we did not developed here, we suppose that the amount of work due for production of an extra output unit has dropped compared to traditional economy, that is to say, the one involving ICT. Consequently, new technologies mentioned upper contribute to reduce costs production for all type of company operating in any business sector (primary, secondary or tertiary).

\section{The Model}

\subsection{Total Cost Functions in the Absence and Presence of ICT}

The traditional cost function is known as, a cost function where work factor and capital factor are not distorted because of the effect of new technologies.

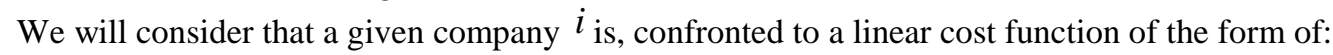

$$
C T_{i}=C(K, L)=\alpha_{i} K+\beta_{i} L+C F_{i}
$$


We will consider that this company is subject to the constraint of the production function of type Cobb-Douglas:

$$
q_{i}=q(K, L)=A_{i} K^{v_{i}} L^{s_{i}}
$$

The variables and parameters involved in the cost and production function are:

- $K$ and $L$ represent respectively the capital factor and the labor factor;

- $C F_{i}$ represents the fixed costs borne by the company $i$;

$A_{i}>0$ is an efficiency parameter (the higher $A_{i}$, the higher the quantities produced, regardless of the combination of factors);

- ${ }^{\alpha} i$ represents the cost of capital or the interest rate;

- $\beta_{i}$ represents the salary or remuneration of the labor factor;

$$
\begin{aligned}
& v_{i}=e_{q_{i} / K}=\frac{\frac{d q_{i}}{q_{i}}}{\frac{d K}{K}} \text { represents the partial elasticity of the product (output) with respect to capital or input } K ; \\
& s_{i}=e_{q_{i} / L}=\frac{\frac{d q_{i}}{d L}}{\frac{q_{i}}{L}} \text { represents the partial elasticity of the product (of the output) with respect to the work or }
\end{aligned}
$$
input $L$.

$L$ represents the partial elasticity of the product (of the output) with respect to the work or to the

The series of examples presented in the above paragraph claim that ICTs can significantly disrupt the structure of production costs.

On the one hand, these examples affirm that we are witnessing a fall in fixed costs in the presence of ICT. If we note $C F_{i}$, the fixed costs of the business $i$ in the traditional economy that is to say in the absence of ICT and $C F_{i}^{*}$ , the fixed costs of the business in the new economy, then we can assume that $C F_{i}^{*} \leq C F_{i}$.

This inequality simply means that fixed costs are lower in an ICT context compared to the traditional economy.

On the other hand, these same examples assert that variable costs in an ICT context are lower compared to variable costs in a traditional economy: the levels (or quantities) of capital and labor input required for the production of an output unit have lower compared to the traditional economy (not taking into account ICT).

It is assumed that modifying the structure (or form) of total costs consists of considering the class of the following cost functions:

$$
C T_{i}=\alpha_{i} K^{u_{i}}+\beta_{i} L^{t_{i}}+C F_{i}
$$
is:

By giving $u_{i}$ the value 1 and also $t_{i}$ the value $1\left(u_{i}=1, t_{i}=1\right.$ ), we find the simple linear cost function, that

$$
C T_{i}=\alpha_{i} K+\beta_{i} L+C F_{i}
$$

It is this form of cost function that we have analyzed in the framework of the traditional economy (not taking into account ICT) above.

If $u_{i} \neq 1$ or $t_{i} \neq 1$, the cost function $C T_{i}=\alpha_{i} K^{u_{i}}+\beta_{i} L^{t_{i}}+C F_{i}$ (3), undergoes a power function type transformation.

With ICT, the number of people likely to move is in clear reduction and consequently the related costs.

To model this idea, we will deform the cost function by means of a coefficient noted $t_{i}$, and which represents the index of ICT such as $0<t_{i} \leq 1$. When $t_{i}$ tends towards zero, we will say that the company uses more and more ICT and when ${ }^{t_{i}}$ tends towards one, we will say that the company uses less and less ICT. is:

By giving $u_{i}$ the value 1 and also $t_{i}$ the value $1\left(u_{i}=1, t_{i}=1\right.$ ), we find the simple linear cost function, that $C T_{i}=\alpha_{i} K+\beta_{i} L+C F_{i}$

Thus the new total cost function of the enterprise $i$ in the presence of ICT becomes: 
The parameters $u_{i}$ and $t_{i}$ in equation (3) respectively show the simple idea that the amount of work due for the production of a unit of output decreased in the cost function when using ICT. In the following, we will use $u_{i}$ and $t_{i}$, indices or parameters of ICT.

The reasoning «all things remaining equal », leads us to consider the class function where by the only labor factor is deformed with the introduction of ICT, the capital factor only adapting to such changes.

$$
C T_{i}=\alpha_{i} K+\beta_{i} L^{t_{i}}+C F_{i}
$$

Company $i$ is facing the following cost function:

$$
C T_{i}^{*}=C(K, L)=\alpha_{i} K+\beta_{i} L^{t_{i}}+C F_{i}^{*} \quad(5), \quad \text { is subjected to the constraint of function }
$$

$q_{i}=q(K, L)=A_{i} K^{v_{i}} L^{s_{i}}$ (2) of Cobb-Douglas type. Company $j$ is subjected to the following cost function:

$$
C T_{j}^{*}=C(K, L)=\alpha_{j} K+\beta_{j} L^{t}+C F_{j}^{*}
$$

$\left(5^{\prime}\right)$, is subjected to the constraint of the de la function

$q_{j}=q(K, L)=A_{j} K^{v_{j}} L^{s} j$

(2) of Cobb-Douglas type.

The program of the company (producer) $i$ in presence ICT is such that:

Min $C V_{i}^{*}=\alpha_{i} K+\beta_{i} L^{t_{i}}$ under constraint of $q_{i}=A_{i} K^{v_{i}} L^{s_{i}}$

Let us form the Lagrangian:

$$
\begin{aligned}
\oiiint^{(K, L, \lambda)}=\alpha_{i} K^{t_{i}}+\beta_{i} L+\lambda\left(q_{i}-A_{i} K^{v_{i}} L^{s_{i}}\right) & \\
\frac{d £}{\partial K}=\alpha_{i} t_{i} K^{t_{i}-1}-\lambda A_{i} v_{i} K^{v_{i}-1} L^{s_{i}}=0 & \Leftrightarrow \alpha_{i} t_{i} K^{t_{i}-1}=\lambda A_{i} v_{i} K^{v_{i}-1} L^{s_{i}} \\
\frac{d £}{\partial L}=\beta_{i}-\lambda A_{i} s_{i} K^{v_{i}} L^{s_{i}-1}=0 & \Leftrightarrow \beta_{i}=\lambda A_{i} s_{i} K^{v_{i}} L^{s_{i-1}} \\
\frac{d £}{\partial \lambda}=q_{i}-A_{i} K^{v_{i}} L^{s_{i}}=0 & \Leftrightarrow q_{i}=A_{i} K^{v_{i}} L^{s_{i}}
\end{aligned}
$$

Solving this program gives the total cost function in the presence of ICT. That is:

$$
\left.C T_{i}^{*}\left(q_{i}\right)=\alpha_{i}\left(1+\frac{s_{i} t_{i}}{v_{i}}\right)\left(\frac{1}{\left(A_{i}^{\left(\frac{1}{v_{i}+s_{i} t_{i}}\right)}\left(\frac{s_{i} \alpha_{i} t_{i}}{v_{i} \beta_{i}}\right)\left(\frac{s_{i}}{v_{i}+s_{i} t_{i}}\right)\right)}\right)^{t^{t_{i}}}\right)^{\left(\frac{t_{i}}{v_{i}+s_{i} t_{i}}\right)+C F_{i}^{*}}
$$

By assigning to $t_{i}$, the value 1, we find the total cost function in the absence of ICT. That is :

$$
\begin{gathered}
C T_{i}\left(q_{i}\right)=\alpha_{i}\left(1+\frac{s_{i}}{v_{i}}\right)\left(\frac{1}{A_{i}^{\left(\frac{1}{v_{i}+s_{i}}\right)}\left(\frac{s_{i} \alpha_{i}}{v_{i} \beta_{i}}\right)\left(\frac{s_{i}}{v_{i}+s_{i}}\right)}\right) q_{i}^{\left(\frac{1}{v_{i}+s_{i}}\right)+C F_{i}} \\
\left.D_{i}=\left(1+\frac{s_{i}}{v_{i}}\right) ; E_{i}=\frac{1\left(\frac{1}{v_{i}+s_{i}}\right)}{A_{i}}\right)\left(\frac{s_{i} \alpha_{i}}{v_{i} \beta_{i}}\right)\left(\frac{s_{i}}{v_{i}+s_{i}}\right)
\end{gathered}
$$




$$
D_{i}^{*}=\left(1+\frac{s_{i} t_{i}}{v_{i}}\right)
$$

$$
\left.E_{i}^{*}=\left(\frac{1}{\left(A_{i}^{\left(\frac{1}{v_{i}+s_{i} t_{i}}\right)}\left(\frac{s_{i} \alpha_{i} t_{i}}{v_{i} \beta_{i}}\right)\left(\frac{s_{i}}{v_{i}+s_{i} t_{i}}\right)\right)}\right)^{t_{i}}\right)^{(}
$$

The total cost functions without and taking into account new information and communication technologies become respectively:

$$
\begin{gathered}
C T_{i}\left(q_{i}\right)=\alpha_{i} D_{i} E_{i} q_{i}^{\left(\frac{1}{v_{i}+s_{i}}\right)}+C F_{i} \\
C T_{i}^{*}\left(q_{i}\right)=\alpha_{i} D_{i}^{*} E_{i}^{*} q_{i}^{\left(\frac{t_{i}}{v_{i}+s_{i} t_{i}}\right)}+C F_{i}^{*}
\end{gathered}
$$

Let us compare the total cost in the absence of ICT noted $C T_{i}\left(q_{i}\right)$, and the total cost in the presence of ICT noted $C T_{i}^{*}\left(q_{i}\right)$

We have shown previously that the fixed costs in the presence of ICTs were lower than the fixed costs in the absence of ICTs. That is: $C F_{i}^{*} \leq C F_{i}$

$$
\begin{aligned}
& \text { Compare } D_{i} \text { and } D_{i}^{*} \\
& D_{i}=\left(1+\frac{s_{i}}{v_{i}}\right) ; D_{i}^{*}=\left(1+\frac{s_{i} t_{i}}{v_{i}}\right)
\end{aligned}
$$

We have admitted that $t_{i}<1$, this implies $\frac{s_{i}}{v_{i}}>\frac{s_{i} t_{i}}{v_{i}}$

On peut donc conclure que $D_{i}^{*}<D_{i}$

$$
\left(\frac{1}{v_{i}+s_{i}}\right) \quad\left(\frac{t_{i}}{v_{i}+s_{i} t_{i}}\right)
$$

Let us now compare the expressions $q i$ and $q_{i}$

appearing respectively in equations (9) and (10).

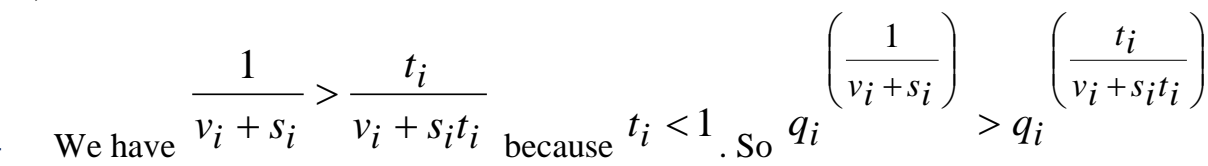

$$
\begin{aligned}
& C F_{i}^{*} \leq C F_{i}, D_{i}^{*}<D_{i} \text {, and } q_{i}^{\left(\frac{1}{v_{i}+s_{i}}\right)}>q_{i}^{\left(\frac{t_{i}}{v_{i}+s_{i} t_{i}}\right)} \\
& \text { We can say that } C T_{i}^{*}\left(q_{i}\right)<C T_{i}\left(q_{i}\right)
\end{aligned}
$$

The index of new technologies $t_{i}$ therefore leads to a modification of the form of the total cost function through:

(a) The slope of the cost function $\left(\alpha_{i} D_{i}^{*} E_{i}^{*}<\alpha_{i} D_{i} E_{i}\right)$

(b) The original data represented here by the fixed cost $C F_{i}^{*} \leq C F_{i}$

(c) The degree of the monomial : ${ }^{q_{i}}: q_{i}<q_{i}$

$$
\left(\frac{t_{i}}{v_{i}+s_{i} t_{i}}\right)\left(\frac{1}{v_{i}+s_{i}}\right)
$$


Note: In the following, we will discuss the competition between companies $i$ and $j$. The examination of the cost equations in the presence and absence of ICT is analogous to that of the company $j$. The parameters concerning the company $j$ are obtained by inversion (replacement) of the index $i$ by the index $j$. Thus, we will have:

$$
\begin{aligned}
& D_{j}=\left(1+\frac{s_{j}}{v_{j}}\right) D_{j}^{*}=\left(1+\frac{s_{j} t_{j}}{v_{j}}\right) ; \quad E_{j}=\frac{1}{A_{j}^{\left(\frac{1}{v_{j}+s_{j}}\right)}\left(\frac{s_{j} \alpha_{j}}{v_{j} \beta_{j}}\right)\left(\frac{s_{j}}{v_{j}+s_{j}}\right)} \\
& E_{j}^{*}=\left(\frac{1}{A_{j}\left(\frac{1}{v_{j}+s_{j} t_{j}}\right)\left(\frac{s_{j} \alpha_{j} t_{j}}{v_{j} \beta_{j}}\right)\left(\frac{s_{j}}{v_{j}+s_{j} t_{j}}\right)}\right)^{t_{j}}
\end{aligned}
$$

\subsection{Cournot Nash's Equilibria in the Absence and Presence of ICT}

Consider two companies $i$ and $j$ in a situation of duopoly of the Cournot type.

Buyers are manifested by a demand function $q=q_{i}+q_{j}=f(p)$

$f(p)$ represents the total quantity purchased from producers if the price is $p . f(p)$ represents the total quantity purchased from producers if the price is. is a simple and classic demand function, that is to say linear and decreasing (with negative slope).

Its expression is such that:

$q=q_{i}+q_{j}=f(p)=a p+b$

With $a<0$ and $b \geq 0 ; p, \mathrm{q}, \in \mathfrak{R}^{+}$

The inverse demand function becomes:

$$
p=f^{-1}(p)=\frac{1}{a}\left(q_{i}+q_{j}\right)-\frac{b}{a}
$$

Question: what quantities of goods $q_{i}$ and $q_{j}$, the producers $i$ and $j$ will they produce?

Each producer seeks to maximize his profit.

$$
\begin{aligned}
& \prod_{i}=P q_{i}-C T_{i}\left(q_{i}\right) \\
& \prod_{j}=P q_{j}-C T_{j}\left(q_{j}\right) \\
& q_{i}+q_{j}=q=f(p)
\end{aligned}
$$

By canceling the partial derivative of each firm with respect to its quantity produced, we obtain the reaction functions of the two firms.

One of the duopolists called "leader" integrates the reaction function of the competitor, called "follower" in his profit function. Canceling this profit function gives the production torque $\left(q_{i}, q_{j}\right)$.

\section{Obtained Results}

When companies $i$ and $j$ get involved into a competition by quantities in an imperfect information situation, these are the following results:

\begin{tabular}{l|l|l}
\hline Case & Couples ICT $\left(t_{i}, t_{j}\right)$ & Couples of production $\left(q_{i}, q_{j}\right)$ \\
\hline 1 & $\left(t_{i}, t_{j}\right)=\left(\frac{1}{3}, \frac{1}{3}\right)$ & $\left(q_{i}, q_{j}\right)=(2,2851 ; 184,8462)$ \\
\hline
\end{tabular}




\begin{tabular}{l|l|l}
\hline 2 & $\left(t_{i}, t_{j}\right)=\left(\frac{1}{3}, \frac{1}{5}\right)$ & $\left(q_{i}, q_{j}\right)=(2,2869 ; 184,8444)$ \\
\hline 3 & $\left(t_{i}, t_{j}\right)=\left(\frac{1}{3}, \frac{1}{7}\right)$ & $\left(q_{i}, q_{j}\right)=(2,2872 ; 184,8441)$ \\
\hline 4 & $\left(t_{i}, t_{j}\right)=\left(\frac{1}{3}, \frac{1}{15}\right)$ & $\left(q_{i}, q_{j}\right)=(2,2874 ; 184,8439)$ \\
\hline 5 & $\left(t_{i}, t_{j}\right)=\left(\frac{1}{3}, \frac{1}{25}\right)$ & $\left(q_{i}, q_{j}\right)=(2,2874 ; 184,8439)$ \\
\hline 6 & $\left(t_{i}, t_{j}\right)=\left(\frac{1}{3}, \frac{1}{35}\right)$ & $\left(q_{i}, q_{j}\right)=(2,2874 ; 184,8439)$ \\
\hline
\end{tabular}

Based on the table above, we realize that the threshold of use of ICT is the couple

$$
\left(t_{i}, t_{j}\right)=\left(\frac{1}{3}, \frac{1}{15}\right)
$$

(case 4)

in the sense that following cases (5 and 6) give the same level of production for companies $i$ and $j$ despite the intensive use of new technologies. This result brings an additional explanation to the Solow paradox which stipulates substantially that: « you can see the computer age everywhere except in the productivity statistics ».

That can be understood as: « machines can be seen everywhere except in the productivity statistics ». Consequently, companies would gain to abstain in investing to acquire ICT from the moment the threshold is reached.

\section{Conclusion}

In this paper, the objective was to show that whether companies get involved unilaterally into the use of new technologies or not, is no more profitable beyond a given threshold. To succeed, we started from the idea of a factor decrease as the company uses ICT. A range of examples has been developed strengthen this idea. The main lesson is the determination of the optimal level of new technologies by companies in a competitive environment. Due to this information, companies will be able to save money and resources. The acquisition of ICT remains a tool in so far as it provides a decisive advantage to the company in terms of profit and market share. This advantage held by companies using ICT depends on the level of information possessed by economic agents.

In fact, in perfect information situation, a company that uses more ICT compared to competitor wins in terms of competitiveness. However, with imperfect information, the knowledge of the reaction function of the competitor wins ICT. In other words, a company can use ICT less than a competitor, but the simple fact of knowing the reaction function of its competitor guarantees a part or market share and a higher profit: which further explains the Solow paradox.

\section{References}

Anderson, J. (2010). ICT transforming education a regional guide. UNESCO: Bangkok.

Beheton (2010). Introduction et Intégration des TIC dans l'Education au Benin. 1 vols. Educational Technology and Research Internationa (e - TRI).

Castells, M. (1998). La société en réseaux. L'ère de l'information. Editions Fayard ednParis.

Dieuzeide, H. (1994). Les nouvelles technologies. Outils d'enseignement. Edition Nathan ednParis.

Njocke, M. (2010). Nouvelles technologies de l'information et de la communication et effets sur la compétitivité des entreprises dans un duopole de Cournot, Mai, Thèse de Doctorat en sciences économiques. Université de Pau et des Pays de l'Adour: France.

Njocke, M. (2020). Robotisation et facteur travail dans le cadre d'une compétition par les quantités en information minimale. Revue Internationale D'économie Numérique, 2(2): Available: https://revues.imist.ma/index.php/RIEN/article/view/24395 